\title{
A reinvenção da escola a partir de uma experiência instituinte em hospital
}

Rejane de Souza Fontes

Universidade Federal Fluminense

\section{Resumo}

O objetivo deste trabalho é refletir sobre a importância do método narrativo e da escuta pedagógica para a construção de discursos alternativos à fala hegemônica na educação, mediante uma atuação docente que investigue sua própria prática. Com base na escuta das falas de crianças hospitalizadas e em leituras de Walter Benjamin, este texto se propõe a subverter o pensamento que tem dominado o cenário educacional no Brasil. Embora esse pensamento hegemônico nos obrigue a acreditar que não existem alternativas, as propostas de reformas são plurais e desmentem a ideologia veiculada pela mídia. Essas reformas nascem na base da sociedade civil e estão articuladas com setores populares, cujos protagonistas são os educadores. As experiências instituintes em escolas públicas e fora delas procuram responder às mudanças de nosso tempo. A sociedade da informação mediática e do bombardeio visual abre mão da reflexão e da análise minuciosa da produção cultural e educacional que a invade, reproduzindo como se fossem dogmas os jargões que a mídia produz. Qual o lugar dos indivíduos excluídos na sociedade do espetáculo? Na sociedade de promessas de lucros fáceis, fama rápida e conhecimentos sem aprendizado? Em meio à complexa cultura informacional de discursos desconectados, o que parece ser comum, para a maior parte das crianças hospitalizadas no Brasil, é que elas são marcadas pelo ciclo da miséria, da exclusão e pela ausência de quem, as permitindo falar, escute suas vozes. Conclui-se que escutar a narrativa dos excluídos conseqüentemente tem implicações na ampliação de experiências educativas que possam contar uma outra história: a de um mundo mais humanizado.

\section{Palavras-chave:}

Educação - Experiências instituintes - Escuta pedagógica - Exclusão.

Correspondência:

Rejane de Souza Fontes

Rua Emília Kill, 78 - Mutondo

24422-650 - São Gonçalo - RJ

e-mail: rejanefontes@ig.com.br 


\section{The reinvention of school from a founding experience in a hospital}

Rejane de Souza Fontes

Universidade Federal Fluminense

Contact:

Rejane de Souza Fontes

Rua Emília Kill, 78 - Mutondo

24422-650 - São Gonçalo - R

e-mail: rejanefontes@ig.com.br

\begin{abstract}
The purpose of this work is to reflect on the importance of the narrative method and of the pedagogical listening to the construction of alternative discourses to the hegemonic messages in education, construction which is to be achieved through teachers' investigation of their own practice. By listening to hospitalized children, and based on readings of Walter Benjamin, this text proposes to challenge the thinking that has dominated the educational scene in Brazil. Even though this hegemonic thinking may have us believe there are no alternatives, the proposals for reforms are varied and refute the ideology disseminated by the media. Such reforms spring from the base of society and are articulated to popular segments whose protagonists are the educators. The founding experiences both inside and outside of public schools seek to respond to the changes of our times. The society of media information and visual bombardment gives up reflecting on and carefully analyzing the cultural and educational production that invade it, reproducing as dogmas the parlance produced by the media. What is the place for excluded individuals in a society of the spectacle? In a society that promises easy profits, rapid celebrity and knowledge without learning? Amidst the complex informational culture of disconnected discourses, what seems to be usual for most hospitalized children in Brazil is that they are marked by the cycle of poverty, exclusion and absence of anybody who, allowing them to speak, listens to their voices. It can be concluded that listening to the narrative of the excluded has consequently implications to the expansion of educational experiences that can tell a different story: that of a more humanized world.
\end{abstract}

\section{Keywords}

Education - Founding experiences - Pedagogical listening Exclusion. 
(...) um ser de uma afetividade intensa e instável, que sorri, ri, chora, um ser ansioso e angustiado, um ser gozador, ébrio, estático, violento, furioso, amante, um ser invadido pelo imaginário, um ser que conhece a morte mas que não pode acreditar nela, um ser que segrega o mito e a magia, um ser possuído pelos espiritos e pelos deuses, um ser que se alimenta de ilusões e de quimeras, um ser subjetivo, cujas relações com o mundo objetivo são sempre incertas, um ser sujeito ao erro e à vagabundagem, um ser lúbrico que produz desordem. (...) Sendo assim, é necessário pensar que o desfraldamento do imaginário, que as derivações mitológicas e mágicas, que as confusões da subjetividade, que a multiplicação dos erros e a proliferação da desordem, longe de terem constituído desvantagens para o Homo sapiens, estão, muito pelo contrário, ligadas aos seus prodigiosos desenvolvimentos (...). (Morin, 2000, p. 59-60)

Cada vez mais presenciamos uma sociedade complexa, na qual vivemos, que tem se configurado como uma sociedade do espetáculo, ${ }^{1}$ do consumo rápido e imediato, em que tudo é fugaz e instantâneo, desde os objetos até as pessoas.

Numa lógica do mercado capitalista que invade os padrões educacionais e éticos de nosso país, os profissionais se vêem à beira de um abismo, encurralados por uma lógica que sempre pede para serem mais do que são e, em contrapartida, não oferece os instrumentos necessários para sua libertação e ascensão profissionais. A qualificação da educação como mercadoria ganha espaço nesta sociedade do consumo e arrasta consigo um forte arcabouço ideológico que desqualifica pessoas, pessoas que tiveram suas vidas tecidas pela escola pública, quer como alunos quer como professores.

A sociedade da informação mediática e do bombardeio visual abre mão da reflexão e da análise minuciosa da produção cultural e educacional que a invade, reproduzindo como se fossem dogmas (reflexos de um pensamento único e hegemônico) os jargões que a mídia produz:
A multidão busca o divertimento sem exercer uma participação ativa e crítica, como o espera Benjamin, mas para esquecer o trabalho alienante. A indústria cultural, então, tem realmente por função distrair os trabalhadores, mas distraí-los da questão essencial de uma transformação das condições sociais de produção, ao fornecer-lhes uma compensação ilusória e passageira. (Gagnebin, 1985, p. 55)

Para Benjamin (Gagnebin, 1985), a prática de narrar histórias está vinculada à experiência coletiva de comunidades em que os indivíduos não se escravizaram à divisão capitalista do trabalho. Nessas sociedades pré-capitalistas a experiência coletiva predomina sobre a experiência individual dos sujeitos. A arte de narrar entrou em declínio em conseqüência do advento da informação. A informação passou a ser a mais importante das funções comunicativas trazendo em si uma explicação fechada em detrimento das narrativas.

Cada manhã recebemos notícias de todo o mundo. E, no entanto, somos pobres em histórias surpreendentes. A razão é que os fatos já nos chegam acompanhados de explicações. Em outras palavras: quase nada do que acontece está a serviço da narrativa, e quase tudo está a serviço da informação. (Benjamin, 1987, p. 203)

Nesta sociedade da informação e do espetáculo, em que ouvir histórias deveria aproximar fisicamente narradores e ouvintes, vivemos um distanciamento solitário proporcionado por uma informação rápida e mediatizada pela TV e pelo computador. Com o surgimento da TV como veículo de informação, inventa-se

1. A expressão sociedade do espetáculo faz referência às idéias contidas na obra de Guy Debord intitulada A sociedade do espetáculo, publicada originalmente em Paris, em 1967, e pela editora Contraponto, no Brasil, trinta anos depois. Como poucos autores que refletem sobre sua época, Debord (1931-1994) analisa a sociedade capitalista contemporânea e apresenta a mercadoria como o grande espetáculo. Para ele "o espetáculo não é um conjunto de imagens, mas uma relação social entre pessoas, mediatizada por imagens" que são pseudo-representações da realidade. 0 espetáculo é, enfim, o coração da irrealidade da sociedade real. 
o sujeito espectador, cujas histórias não pode mais narrar. Silenciado pelo texto televisivo, o sujeito da era da informação é impossibilitado de interagir com as narrativas que ouve e que contam sempre grandes feitos e grandes fatos.

A sociedade do espetáculo chocou os processos de comunicação que alimentavam os circuitos de narração. 0 impacto da imagem parece ter calado as vozes que dialogavam e insurgiam contra o pensamento único da pósmodernidade, tornando o homem cada vez mais solitário num mundo globalizado. Esse pensamento foi muito bem ilustrado nas palavras de Oliveira (2002) quando disse que "a sociedade de hoje não é coletiva, ela é formada por indivíduos".

Para Zemelman (2002) um grande de número de pessoas é excluído da informação. Todavia, elas não têm consciência de que não têm informação. "Não há necessidade de pensar porque não há necessidade de ser pessoa”. Segundo ele, vivemos num processo de atomização social. E acaba também por concluir que "não há sociedades, apenas indivíduos”.

Qual o lugar dos indivíduos excluídos ${ }^{2}$ na sociedade do espetáculo? Na sociedade de promessas de lucros fáceis, fama rápida e conhecimentos sem aprendizado?

Nosso centro de interesse, neste artigo, volta-se para práticas educativas alternativas materializadas em escutas pedagógicas (Ceccim; Carvalho, 1997) dentro de espaços hospitalares, as quais propõem o conhecimento como uma forma de conforto emocional à criança enferma que sofre com a internação e o desconhecimento do ambiente hospitalar. Acreditamos que essa prática possui traços que a configuram como uma experiência instituinte, ${ }^{3}$ capaz de dar voz aos "excluídos" mas que em vez de se dar na escola pública, acontece num outro espaço público: o hospital. ${ }^{4}$

A classe hospitalar contemporânea, além de atender às necessidades pedagógico-educacionais da criança e do adolescente hospitalizados (necessidades provenientes de atenção integral ao seu crescimento e desenvolvimento), obedece aos fundamentos políticos da educação, isto é, ratifica o respeito aos princípios democráticos da igualdade, da liberdade e da valorização da dignidade humana. (Ceccim, 1999, p. 31-32)

A escola, que era sagrada e desejada, tornou-se ultrapassada diante da frenética inovação tecnológica do mundo contemporâneo, dessa sociedade instantânea da imagem e do espetáculo, em que os valores cultivados são os do mercado de consumo e a lógica eleita, a do impacto. Embora as estatísticas oficiais demonstrem, a cada ano, maior ingresso de alunos das camadas populares nas redes oficiais de ensino, o conhecimento formal como moeda de troca, agora como antes, continua pertencendo a círculos restritos da sociedade. Isso pode ser atestado pela diferença no nível da qualidade do ensino ministrado em escolas públicas e particulares, cujo conteúdo parece não ser atrativo para as maiorias, que se contentam com o entretenimento fugaz e superficial dos programas que noticiam os bastidores do mundo artístico e os reality shows nacionais.

Assim, Benjamin (1987) se manifesta sobre a velocidade da (in)comunicação dos tempos modernos e que podemos transpor para o mundo escolar:

A experiência transmitida pelo relato deve ser comum ao narrador e ao ouvinte. Pressupõe, portanto, uma comunidade de vida e de discurso que o rápido desenvolvimento do capitalismo, da

2. 0 termo excluído assume aqui a conotação de privação de acesso aos bens materiais e culturais produzidos pela sociedade contemporânea e destinados a uma parcela de sua população que pode pagar por estes serviços/mercadorias. Exclusão material e exclusão cultural constituem, assim, os dois lados de uma mesma moeda, estabelecendo entre si uma relação dialética que se influencia mutuamente. Ou seja, a exclusão material engendra, na maioria dos casos, a exclusão aos bens culturais e de saúde, ao mesmo tempo em que a exclusão a estes últimos dificulta 0 acesso aos bens materiais produzidos e valorizados socialmente.

3. Os movimentos instituintes têm como característica reinventar processos de ensinar e aprender, como exercícios de autonomia e fortalecimento de inteligências coletivas.

4. A experiência instituinte a que fazemos menção neste artigo e que é objeto de nossa reflexão desenvolveu-se na enfermaria pediátrica do Hospital Universitário Antônio Pedro em Niterói, no Rio de Janeiro. 
técnica, sobretudo, destruiu. A distância entre os grupos humanos, particularmente entre as gerações, transformou-se hoje em abismo porque as condições de vida mudam em um ritmo demasiado rápido para a capacidade humana de assimilação. Enquanto no passado o ancião que se aproximava da morte era o depositário privilegiado de uma experiência que transmitia aos mais jovens, hoje ele não passa de um velho cujo discurso é inútil. (Gagnebin, 1987, p. 10)

0 autor nos fala aqui que a "comunidade da experiência funda a dimensão prática da narrativa tradicional" (Gagnebin, 1987, p.11). A pessoa que conta transmite um saber que seus interlocutores podem receber com algum proveito. Esta sapiência prática toma, muitas vezes, a forma de uma lição, de um conselho ou de uma advertência. Essa forma de comunicação parece estar desaparecendo, pois hoje não sabemos mais como orientar, através do diálogo, pessoas de gerações diferentes da nossa, como nossos alunos, "de tão isolados que estamos, cada um em seu mundo particular e privado" (Gagnebin, 1987, p.11).

Em meio a esse bombardeio informacional, muitas vezes, irrefletido, a instituição escola e com ela, seus profissionais, têm sofrido de um obsoletismo crônico acompanhado de freqüentes turbulências internas entre os que lutam para sobreviver e os que já se renderam a uma guerra ideológica (in)visível.

E o professor? E a professora? Esses parecem erigir estratégias que oscilam entre a resistência (coletiva ou individualmente referenciada) e a desistência, o desânimo, a alienação. Tratase de um campo histórico e quotidianamente minado por onde projetos são semeados, ceifados, reconstruídos. Caminhar por esses campos, hoje, requer basicamente a compreensão de que a identidade do profissional da educação no Brasil, se compõe, antes de mais nada, a partir da definição de políticas públicas, no campo da educação e para além dele. (Simões; Carvalho, 2001, p. 32)
Rememorando e contando histórias sobre os processos educativos de ontem e de hoje, as pesquisas em Educação e, particularmente, em Educação Especial, devem buscar resgatar a potencialidade de vozes emudecidas pela historiografia e pela política oficiais, provocando o encontro de experiências tecidas a partir de fios históricos que evocam lembranças e que trazem o potencial da mudança nos pequenos detalhes de uma história que se constrói cotidianamente.

\section{A (re)invenção da escola}

Como muito bem nos aponta linhares (2000/2001), os movimentos instituintes não nascem em redomas de vidro, não crescem isolados da vida, da história, das ações coletivas e individuais, mas se alimentam de circuitos incessantes de religação entre passado e futuro, entre as diferentes disciplinas, entre afetos, linguagens, emoções, saberes e conhecimentos. É por isso que esses movimentos estouram nos mais diferentes espaços e tempos da vida.

Como uma proposta de inclusão dos que estão social e educacionalmente excluídos devido a uma enfermidade, poderíamos afirmar que a contribuição do acompanhamento pedagógico em hospital para o bem-estar da criança hospitalizada passa por duas vertentes de análise. Primeiro, porque este tipo de atividade, ao acionar o lúdico como canal de comunicação com a criança hospitalizada, procura fazê-la esquecer, durante alguns instantes, do ambiente agressivo no qual se encontra, resgatando sensações da infância vivida anteriormente à entrada no hospital. Segundo, porque ao conhecer e desmitificar o ambiente hospitalar, re-significando suas práticas e rotinas, que é uma das propostas de atendimento pedagógico em hospital, o medo que paralisa as ações e cria resistência, tende a desaparecer, surgindo em seu lugar a intimidade com o espaço e a confiança naqueles que cuidam dela.

Em uma sociedade com forte ênfase visual centrada no espetáculo, Ceccim (1997) nos 
falará da "escuta pedagógica para agenciar conexões, necessidades intelectuais, emoções e pensamentos" e que pensamos ser um conceito importante para ser recuperado neste texto. Segundo ele,

0 termo escuta provém da psicanálise e diferencia-se da audição. Enquanto a audição se refere à apreensão/compreensão de vozes e sons audíveis, a escuta se refere à apreensão/compreensão de expectativas e sentidos, ouvindo através das palavras, as lacunas do que é dito e os silêncios, ouvindo expressões e gestos, condutas e postura. A escuta não se limita ao campo da fala ou do falado, ao contrário, busca perscrutar os mundos interpessoais que constituem nossa subjetividade para cartografar o movimento das forças de vida que engendram nossa singularidade. (Ceccim, 1997, p. 31)

Essa escuta pedagógica de que nos fala Ceccim deve transcender o físico, aparentemente imediato e adentrar o mundo silencioso ou silenciado das subjetividades da criança enferma. Desse modo, a escuta se materializa numa perspectiva de atenção integral como escuta à vida, resgatando o conceito de saúde como afirmação da própria vida.

Começamos a perceber nesse contexto inter-subjetivo do hospital, em que se interpenetram os conceitos de educação e saúde, uma nova perspectiva de educação que fertiliza a vida, pois sabemos que o desejo de aprender/conhecer engendra o desejo de viver no ser humano.

Ao mesmo tempo em que a hospitalização é um acontecimento permeado por situações de medo e tristeza, que tem o potencial de paralisar o processo de construção de conhecimento,

Uma adequada possibilidade de acolhimento dos medos, desejos, ansiedades, confusões e ambivalências, com adequado nível de informação, permitirá, portanto, a produção de conhecimentos sobre si e uma construção positiva a respeito da saúde, em que o corpo não se separe do pensamento. (Ceccim, 1997, p. 34)
Nessa perspectiva, a abordagem pedagógica pode ser entendida como instrumento de suavização dos efeitos traumáticos da internação hospitalar e do impacto causado pelo distanciamento da criança de sua rotina, principalmente no que se refere ao afastamento escolar. 0 período de hospitalização é transformado, então, num tempo de aprendizagem, de construção de conhecimento e aquisição de novos significados, não sendo preenchido apenas pelo sofrimento e o vazio do não desenvolvimento afetivo, psíquico e social.

A atuação do pedagogo em hospital deve ultrapassar a experiência escolar e atingir níveis diferenciados de educação.

Nesse sentido, educação é o conjunto das ações, processos, influências, estruturas, que intervêm no desenvolvimento humano de indivíduos e grupos na sua relação ativa com o meio natural e social, num determinado contexto de relações entre grupos e classes sociais. É uma prática social que atua na configuração da existência humana individual e grupal, para realizar nos sujeitos humanos as características de "ser humano". (Libâneo, 2000, p. 22)

Ainda segundo este autor, cumpre distinguir diferentes manifestações e modalidades de prática educativa, tais como a educação informal, não-formal e formal. A educação conhecida como não-formal seria a realizada em instituições educativas fora dos marcos institucionais, mas com certo grau de sistematização e estruturação pedagógica.

Se há muitas práticas educativas, em muitos lugares e sob variadas modalidades, há, por conseqüência, várias pedagogias: a pedagogia familiar, a pedagogia sindical, a pedagogia dos meios de comunicação, etc.; e também a pedagogia escolar. (Libâneo, 2000, p. 23-24)

Não é mais possível afirmar que o trabalho pedagógico se reduz ao trabalho docente nas escolas. Em resumo, estamos diante de uma 
sociedade genuinamente pedagógica (Beillerot, 1985 apud Libâneo, 2000). Então por que não haver uma pedagogia hospitalar, com princípios, métodos e avaliações diferenciadas da pedagogia escolar oficial, engendrada pela especificação do próprio contexto que a alimenta?

Essa discussão desdobra-se inevitavelmente na formação desse profissional de educação para atuar junto à criança hospitalizada. 0 universo desta ainda é pouco conhecido nas instâncias educacionais de formação pedagógica e, portanto, pouco explorado como locus próprio de atuação do professor e local de aprendizagem.

Como pano de fundo da investigação ora apresentada não poderíamos deixar de pensar acerca da vinculação entre a formação do professor e sua prática pedagógica em hospital. Quais são as pontes que unem e os abismos que separam a formação inicial e a vivência educativa? Como formar professores nas universidades preparando-os para um exercício de autonomia, com “vocação para serem mais” (Freire, 1998), para transcenderem a teoria que a faculdade lhes oferece e chegarem a uma prática realmente emancipadora?

Afinal uma formação de professores, que possa apoiar e instrumentalizar uma refundação emancipatória da escola, não pode deixar de atender às exigências éticas e epistemológicas de religar os saberes, preparando um outro tipo de cultura mais cooperativa, mais participante e mais interligada (Linhares, 2001/2002). E é exatamente isso que procuramos estabelecer por meio da interdisciplinaridade na prática pedagógica hospitalar.

De acordo com esse novo enfoque educacional, sugerimos a prática de uma educação para o afeto ao lado da secular educação para o conhecimento. E também convidamos à reflexão sobre as novas possibilidades de se pôr em prática a relevância da interdisciplinaridade, que ainda conhecemos apenas teoricamente. A nosso ver a continuidade de um atendimento educacional em âmbito hospitalar certamente dependerá do empenho com que os diferentes profissionais e pesquisadores encarem a qualidade de vida da criança enferma. E principalmente do pedagogo que deve ter a sensibilidade de respeitar o sofrimento, o medo, o anseio, a dor, a agressividade, a alegria, a depressão, enfim, todos os sentimentos da criança doente durante as atividades pedagógicas, além de lhe dar a oportunidade de expressar-se, que dá a certeza da continuidade da vida!

A crise por que passa a educação brasileira hoje não é só econômica e financeira, ela perpassa a própria sociedade e seus valores culturais e éticos e irrompe na instituição escolar de um modo geral, e na escola pública, em particular. Onde a população infanto-juvenil marcada para sobrar, fica silenciosamente depositada, aguardando sua vez de ser excluída: primeiro do sistema educacional e demais acessos a bens culturais e de informação crítica e, mais tarde, da sociedade civil e do mundo do trabalho, sendo jogada à margem da história. Entendemos aqui o conceito de história como nos propõe Walter Benjamin em que "a história é objeto de uma construção cujo lugar não é o tempo homogêneo e vazio, mas um tempo saturado de 'agoras'” (1987, p. 229).

Mas tão perigoso quanto o silêncio são as práticas discursivas vazias e inférteis que paralisam as ações e adiam as transformações. Afinal, um discurso que não penetra a prática, nem a fertiliza, morre. Um exemplo bastante claro delas são as políticas públicas e algumas pesquisas acadêmicas que não foram e não são capazes de dialogar com significados educacionais construidos visceralmente pela sociedade. Zemelman (2002) nos alerta que o conhecimento é construido sem saber para que é construído. Para ele, o conhecimento sem função social se aliena de si mesmo.

Trata-se, primeiro, de perguntarmos qual o sentido "necessário" e prático das investigações que se fazem nas faculdades, centros, mestrados e doutorados de educação? (...) Trata-se de indagar sobre o sentido histórico, social, político e técnico de nossas pesquisas. A serviço de que 
e de quem despendemos nosso tempo, nossas forças, e grande parte de nossa vida? (Frigotto, 1989, p. 83)

Contudo, a experiência escolar continua sendo para a grande maioria das crianças e jovens pobres uma experiência dura e muito pouco fértil para a formação de um sentido para suas vidas, que possa traduzir-se em participação cidadã, contribuindo para reinventar a educação e a sociedade brasileira. E é esta a proposta que trazemos para o campo de investigação com o atendimento pedagógico em hospital, em que procuramos ressignificar pedagogicamente a experiência de internação hospitalar sofrida pela criança, extraindo da realidade vivida o maior número possível de conhecimentos oferecidos pela situação em questão.

Esse pode ser um passo importante para tentar diminuir o fosso existente entre o conhecimento pedagógico acadêmico e sua aplicação na prática escolar, no sentido de trazer para o debate o que vem sendo produzido nas fronteiras do conhecimento, através de um exercicio permanente de leitura do mundo, como um convite para uma intervenção solidária de caráter inclusivo em sua construção, valorizando as conexões entre saberes e fazeres.

Em meio a esse caos que parece assolar a educação contemporânea, o professor está buscando espaços alternativos de afirmação de sua autonomia, cujo desejo se expressa nos isolados e ainda tímidos movimentos pedagógicos instituintes dentro e fora das escolas.

Em meio ao cotidiano da escola, onde estão instaladas rotinas e irrompem movimentos clandestinos - não autorizados com suas porções de destruição ou de recriação -, transitam tradições e inovações que precisam ser problematizadas, observadas e apropriadas por aqueles que fazem a escola. (Linhares, 1999, p. 181)

Enfim, ao estudar as experiências instituintes na educação, busca-se seus endereçamentos à constituição de uma outra ordem de racionalidade e de política que leve em consideração outros espaços educativos que transcendam os muros escolares. O hospital como espaço educativo para as crianças hospitalizadas também constitui uma experiência instituinte, mediante uma nova cultura educacional dentro ou fora da escola e está, portanto, referida a um tipo de (re)invenção narrativa que se alimenta de sonhos de justiça e igualdade que, embora sempre renováveis, tantas vezes foram dados como vencidos na história contada a partir da ótica dos vencedores. Para Benjamin (1987), a história é a narrativa do vencedor. A tarefa da educação é também revelar e resgatar essas possibilidades esquecidas, mostrar que o passado comportava outros futuros além deste que realmente ocorreu.

A empresa crítica converge, assim, para a questão da memória e do esquecimento, na luta para tirar do silêncio [através da narrativa] um passado que a história oficial não conta. (Gagnebin, 1985, p. 60)

\section{O "novo"5 conhecimento no século do espetáculo}

0 importante é perceber a criança e seus familiares como seres pensantes que, quando chegam ao hospital, já trazem uma história de vida, um conhecimento prévio e, às vezes, deturpado, sobre o que é saúde, doença e sobre sua ação na dinâmica saúde/doença.

Vislumbramos aí pontas do iceberg do novo paradigma do conhecimento sinalizado por Santos (1987) em que

A ciência pós-moderna tenta, pois, dialogar com outras formas de conhecimento deixando-se penetrar por elas. A mais importante de todas é o co-

5. 0 destaque entre aspas refere-se à idéia inspirada em Linhares (2001/ 2002) de que o conhecimento assim como as experiências instituintes não são fruto de idéias miraculosas, espetaculares e inaugurais, que surgem de uma para outra hora. "Os movimentos capazes de anunciar o novo não podem ser decretados de fora para dentro (...) sua validade e legitimação vêm de movimentos históricos que carregam sonhos, desejos e projetos de saberes e conhecimentos. (p. 23-24)" 
nhecimento do senso-comum, o conhecimento vulgar e prático com que no cotidiano orientamos as nossas ações e damos sentido à nossa vida. (...) É certo que o conhecimento do senso comum tende a ser um conhecimento mistificado e mistificador mas, apesar disso e apesar de ser conservador, tem uma dimensão utópica e libertadora que pode ser ampliada através do diálogo com o conhecimento científico. (Santos, 1987, p. 55-56)

Com a sabedoria que lhe é adjetiva, Santos desconstrói o mito da ciência moderna para reconstruí-lo sob nova roupagem e conteúdo como o novo paradigma da ciência pós-moderna. Nele, há um resgate das diferentes formas de conhecimento que o homem foi obrigado a abandonar ao longo de sua história em nome de um conhecimento tão parcial quanto os demais, chamado "ciência". Encontramos em suas idéias um manancial de saber, no qual nos abrigamos e repousamos provisoriamente em nossa caminhada rumo ao conhecimento de nosso fazer/pensar pedagógico/científico. Nele vislumbramos que o pedagogo seria então o interlocutor privilegiado desses dois conhecimentos em âmbito hospitalar.

0 pedagogo deve utilizar atividades diversas, com o objetivo de favorecer a construção de uma pedagogia que consiga transformar o conhecimento científico e o conhecimento popular em um somatório de possibilidades de forma que, deste encontro, se possibilite o auto-conhecimento do paciente, e que este se reconheça como co-autor do processo emancipatório de definições e escolhas de seu tratamento.

Quanto mais for levado a refletir sobre a sua situacionalidade sobre o seu enraizamento espaço-temporal, mais emergirá dela conscientemente carregado de compromisso com a sua realidade, da qual, porque é sujeito, não deve ser simples espectador, mas deve intervir cada vez mais. (Freire, 1993, p. 61)

É preciso reconhecer a criança hospitalizada e todas as crianças excluídas como agen- tes promotores de sua própria saúde e educação, passando de objeto a sujeito de seu conhecimento que, por meio de sua narrativa de vida, compreende, interfere e interage num mundo de conhecimentos fugazes e, muitas vezes, pouco compreensíveis.

\section{Para (não) concluir...}

Nunca a mesma água, sempre o mesmo rio.

Nunca as mesmas flores, sempre a primavera.

Confúcio

A educação não pode ser a mesma em todas as épocas e lugares devido a seu caráter socialmente determinado. Esse raciocínio muitas vezes enfraqueceu o caráter epistemológico da educação ao longo da história das ciências, ao retirar dela a previsibilidade e recorrência de seus acontecimentos. Hoje, no entanto, a inovação e a pluralidade de fatos e idéias no mundo contemporâneo parecem ressurgir como um dos pilares mais fortes da identidade educacional em nosso país e no mundo.

Lembramos com Candau (1999) que, na América Latina, verificam-se hoje enorme efervescência e criatividade em todos os níveis dos processos pedagógicos e da prática educativa. Embora o pensamento hegemônico nos obrigue a acreditar que não existem alternativas, as propostas de reformas são plurais e desmentem a ideologia veiculada pela mídia. Essas reformas nascem na base da sociedade civil organizada e estão articuladas com amplos setores populares, cujos protagonistas são os educadores. A educação, assim construída, reflete o pluralismo cultural de nosso continente e não pode ser reduzida à formação de consumidores competentes.

0 reconhecimento da complexidade da vida e, em particular, da vida social representou um espaço de confluência entre vários campos do saber. Isso é inegável! Não há mais dúvida de que as experiências instituintes em escolas públicas e fora delas procuram responder às mudanças e perplexidades de nosso tempo, que as práticas instituídas de cima para baixo já não dão 
mais conta de solucionar, pois se tornaram elas mesmas problemáticas e obsoletas diante dos desafios desse admirável mundo novo da tecnologia do espetáculo, da informação e da semiótica diante do qual, lembrando Benjamin (1987) e Bauman (2000), é preciso estar alerta para não submergir a parâmetros informacionais:

A sociedade contemporânea, chamada sociedade do conhecimento e da comunicação, está criando, contraditoriamente, cada vez mais incomunicação e solidão entre as pessoas. (...) 0 mundo virtual criou um habitat para o ser humano, caracterizado pelo encapsulamento sobre si mesmo e pela falta do toque, do tato e do contato humano. (Boff, 1999, p. 11)

Com toda essa complexa cultura informacional de falas e discursos contraditórios e desconectados, o que parece ser comum, para a maior parte das crianças e adolescentes pobres hospitalizados, é que eles são marcados por apresentarem o ciclo da miséria, da internação e da re-internação nos hospitais e pela ausência de quem, permitindo que eles falem, escute suas vozes. Escutar a narrativa dos excluídos conseqüentemente tem implicações na ampliação de experiências que podem contar uma outra história, esquecida pelo relato dos vencedores: a de um mundo mais humanizado.

0 direito a ter um acompanhamento pedagógico em hospital já é conhecido em lei (Brasil, 1994, 1996, 2001), mas não foi reconhecido pela prática e ampliado a todas as crianças hospitalizadas deste país. 0 direito a um trabalho pedagógico de boa qualidade em hospital nasce atrelado ao movimento de humanização que objetiva um atendimento mais igualitário e menos excludente em hospitais, capaz de enxergar o paciente como sujeito integral e não como conjunto de peças anatômicas. Esse movimento deveria ultrapassar os hospitais e ganhar a sociedade que, de várias formas (física, emocional e cognitiva), violenta a saúde de seus cidadãos, como também deveria invadir a escola e possibilitar a inclusão de crianças que, embora estejam matriculadas, têm doenças crônicas e precisam se afastar periodicamente da escola para serem hospitalizadas.

Paula (2002) nos lembra da importância psicossocial deste trabalho quando se refere a dois ícones da história de luta por justiça social em nosso país:

0 que seria da história brasileira se grandes personagens como Betinho e seu irmão Henfil, que foram crianças e posteriormente adultos hemofílicos, pessoas sensíveis, que devem ter tido muitas dificuldades em suas infâncias e em seus processos de escolarização, devido às suas patologias, suas “diferenças”, tivessem sido excluídos do sistema escolar? Certamente a história do Brasil teria tido menos graça sem os cartuns de Henfil e a solidariedade de Betinho. Possivelmente, essas pessoas tiveram a oportunidade de encontrar educadores que souberam estimular as possibilidades e competências desses seres. (p. 16)

Reforçamos nossa tese de uma educação para a emoção. Ao lembrar Elias (1994), para quem razão e emoção não estão em dois lugares contraditórios, mas se constituem simultaneamente, é que precisamos de professores que se formem continuamente no exercício de religar os saberes da escola com os sabores da vida, como ferramentas de solidariedade para os sofrimentos e esperanças humanas. A saúde é muitas vezes conseqüência da atitude e de poder ser feliz, de se sentir incluído numa sociedade excludente.

Enfim, sabemos que o espectro de que tratam essas questões é muito mais amplo nesta sociedade complexa do espetáculo e do consumo. Todavia, num mundo fugaz de afirmações cambaleantes, fica a certeza de que nos princípios da reinvenção da escola está o gene para a reinvenção da sociedade.

Un mundo bueno, insistían, no había sido dado a los seres humanos como un regalo, sino que los propios seres humanos tenían que conquistarlo. (Elias, 1994b, p. 106) 


\section{Referências bibliográficas}

BAUMAN, Z. Globalização: as conseqüências humanas. Rio de Janeiro: Jorge Zahar, 2000.

BENJAMIN, W. Magia e técnica, arte e política: ensaios sobre literatura e história da cultura. Tradução Sérgio Paulo Rouanet. São Paulo: Brasiliense, 1987. (Obras escolhidas, v. 1).

BOFF, L. Saber cuidar: ética do humano, compaixão pela Terra. Petrópolis: Vozes, 1999.

BRASIL Secretaria Nacional de Educação Especial (MEC). Política Nacional de Educação Especial: livro 1. Brasília: SNEE, 1994. $66 \mathrm{p}$.

Lei n. 9394, de 20 de dezembro de 1996. Lei de Diretrizes e Bases da Educação. Diário Oficial da República Federativa do Brasil. Brasília, DF, 23 dez 1996, n. 248.

Resolução CNE/CEB n. 2, 11 set 2001. Diretrizes Nacionais de Educação Especial. Brasília, DF.

CANDAU, V. M. Reformas educacionais hoje na América Latina. In: MOREIRA, A. F. B. Currículo: políticas e práticas. Campinas: Papirus, 1999. p. 29-42.

CECCIM, R. B. Classe hospitalar: buscando padrões referenciais de atendimento pedagógico-educacional à criança e ao adolescente hospitalizados. Revista Integração, Brasília, v. 9, n. 21, p. 31-40, 1999.

CECCIM, R. B.; CARVALHO, P. R. A. (Org.) Criança hospitalizada: atenção integral como escuta à vida. Porto Alegre: Editora da Universidade/UFRGS, 1997.

ELIAS, N. A sociedade dos indivíduos. Rio de Janeiro: Zahar, 1994.

Conocimiento y poder. Tradução Julia Varela. Madrid: La Piqueta, 1994b.

FREIRE, Paulo. Educação e mudança. São Paulo: Paz e Terra, 1993.

Pedagogia da autonomia: saberes necessários à prática docente. Rio de Janeiro: Paz e Terra, 1998.

FRIGOTTO, G. 0 enfoque da dialética materialista histórica na pesquisa educacional. In.: FAZENDA, I. Metodologia da pesquisa educacional. São Paulo: Cortez, 1989. p. 69-90.

GAGNEBIN, J. M. Walter Benjamin: os cacos da história. São Paulo: Brasiliense, 1985.

Prefácio. In.: BENJAMIN, W. Magia e técnica, arte e política: ensaios sobre literatura e história da cultura. Tradução Sérgio Paulo Rouanet. São Paulo: Brasiliense, 1987. (Obras escolhidas, v. 1)

LIBÂNEO, J. C. Pedagogia e pedagogos, para quê? São Paulo: Cortez, 2000.

LINHARES, C. F. Experiências instituintes em escolas públicas: memórias e projetos para formação de professores I. Relatório de Pesquisa CNPq. Niterói: UFF, 2001. Mimeografado.

Experiências instituintes em escolas públicas: memórias e projetos para formação de professores II. Relatório de Pesquisa CNPq. Niterói: UFF, 2002. Mimeografado.

Um continente a ser apropriado: a escola que somos. In.: Políticas do conhecimento: velhos contos, novas contas. Niterói: Intertexto, 1999. p. 171-182.

MORIN, E. Os sete saberes necessários à educação do futuro. São Paulo/Brasília: Cortez/Unesco, 2000.

OLIVEIRA, F. Garantir direitos, verbas públicas e vida digna: uma outra educação é possível. In: CONGRESSO NACIONAL DE EDUCAÇÃO, 4., 2002, São Paulo. Palestra de abertura... São Paulo: Palácio das Convenções do Anhembi, 2002. Não foi publicado. 
PAULA, E. M. A. T. de Crianças e professores em hospitais: aprendizes especiais na diversidade dos contextos hospitalares. In.: ENCONTRO NACIONAL DE DIDÁTICA E PRÁTICA DE ENSINO, 11., 2002, Goiânia. Anais eletrônicos... Goiânia, 2002. Disponível em: CD-Rom.

SANTOS, B. de S. Um discurso sobre as ciências. Porto: Afrontamento, 1987.

SIMÕES, R. H. S.; CARVALHO, J. M. Construção da identidade do professor no Brasil: um olhar histórico. In.: LINHARES, C. et al. (Orgs.) Os lugares dos sujeitos na pesquisa educacional. 2. ed. Campo Grande, MS: UFMS, 2001, p. 438-449.

ZEMELMAN, H. Conferência: Produção do Conhecimento e Educação: História e Utopias. In: SEMINÁRIO NACIONAL DE PÓSGRADUAÇÃO EM EDUCAÇÃO, 2., 2002, Rio de Janeiro. Palestra abertura... Niterói, RJ: Auditório Florestan Fernandes da Faculdade de Educação da UFF, 2002. Não foi publicado.

Recebido em 25.08.03

Modificado em 08.12 .03

Aprovado em 10.02.04

Rejane de Souza Fontes concluiu o mestrado em Educação pela Universidade Federal Fluminense em 2003. Atualmente é professora da Universidade Federal Fluminense. Atua na área de Educação, com ênfase em Educação Especial e Didática. 